\title{
Predicting User Satisfaction of Non-volitional Enterprise Systems: An Example From Telecomunications
}

\author{
Paul A. J. Mason \\ Shinawatra University, Pathum Thani, Thailand \\ Akaret Tangsuwan \\ Convergsys, Bangkok, Thailand
}

\begin{abstract}
The rapid pace of technological change has seen information and communication technologies become the digital backbone of developed nations' economies and a pre-requisite for global trade. Some enterprise systems are however more than mere facilitators, they provide the bedrock without which organizations could not function; we term these mandatory systems "non-volitional" (NVS). With hyper-growth in demand for connectivity, telecommunications are typical of sectors where NVS shape the fiercely competitive landscape. Among them, Billing \& Revenue Management Systems (BRMS) are a form of credit, providers deliver a service and subscribers later pay for that service. As such, they are “business critical”, meaning failures may affect an organization's ability to conduct its core business. Failures also impact user satisfaction, a key measure of information systems success. However, relatively few studies empirically test this notion; fewer still evaluate it at organizational (rather than individual) level, while there is a dearth of literature investigating non-volitional systems and, to the best of our knowledge, none whatsoever consider ways of predicting user satisfaction for BRMS. According to a renowned and widely cited conceptual model, user satisfaction is influenced by information, system, and service quality respectively. To test this theory for telecoms BRMS, we applied structural equation modelling to investigate which of these dimensions has the most effect. The results indicate that information quality, system quality, service quality, and user satisfaction are all valid measures of BRMS success. Hypothesized relationships between the four success dimensions were significantly substantiated. The study also identified five measures of information quality, four measures of system quality, four measures of service quality, and four measures of user satisfaction. Once the proposed model had been successfully validated, we tested the level of significance among user satisfaction and the three quality dimensions. Findings showed that service quality had the strongest influence on user satisfaction, with information quality second. This is quite different from other applications considered in our literature review which mostly have information quality as having the strongest impact (knowledge management systems apart).
\end{abstract}

Keywords: Billing \& Revenue Management Systems success, non-volitional systems, organizational impact, user satisfaction measures, information quality, system quality, service quality

\section{Introduction}

Paul A. J. Mason, Ph.D., assistant professor, School of Science \& Technology, Shinawatra University, Pathum Thani, Thailand. Akaret Tangsuwan, Ph.D., Convergsys, Bangkok, Thailand.

Correspondence concerning this article should be addressed to Paul A. J. Mason, School of Science \& Technology, Shinawatra University, Main Campus, 99 Moo 10, Bangtoey, Samkok, Pathumthani 12160, Thailand. 
The 2010s have been marked by a number of breathtaking technological innovations-Ambient Systems, Block Chain, and Pervasive Computing - a technological tsunami that has long since rendered trusty benchmarks, like Moore's law irrelevant. Such rapid advances have resulted in unprecedented utilization of information and communications technology, the digital backbone of developed nations' national economies, and a pre-requisite for global trade. Some enterprise systems are however more than mere facilitators, they provide the bedrock without which organizations and the sectors in which they operate simply could not function; we term these mandatory systems "non-volitional” (NVS).

A recent report on the future of telecoms referred to them as the "enabler of digitization and disruptor-in-chief of everything, from business and operating models across converging industries, to the global economy” (Pati, Dadhich, Basile, \& Schreiber, 2017, p. 3). With hyper-growth in demand for connectivity, telecommunications are typical of sectors where NVS shape the fiercely competitive landscape; network providers "battle" relentlessly for subscriber retention and growth thru rolling tuning of promotion, campaign, and service portfolios. The corollary is to turn up the heat on their Billing \& Revenue Management Systems (BRMS), a form of credit-providers deliver a service and subscribers later pay for that service. In boardroom parlance, BRMS are termed "business critical”, meaning any failure may affect an organization's ability to conduct its core business. ${ }^{1}$

Failures also impact user satisfaction, a key measure of information systems success. Understanding the determinants of BRMS success, in particular improving levels of user satisfaction, would help companies leverage such factors on future implementations. However, relatively few studies empirically test this notion; fewer still evaluate it at organizational (rather than individual) level, while there is a dearth of literature investigating non-volitional systems and, to the best of our knowledge, none whatsoever consider ways of predicting user satisfaction for BRMS.

One solution is to apply the highly influential success model by DeLone and McLean (2003), determine whether that model can (or needs to) be extended/modified for BRMS, and then evaluate which factors have most bearing on user satisfaction. The model itself provides an excellent theoretical basis for understanding IS success generally by considering interrelationships among six critical dimensions. Therefore, in this study, which builds on a pilot survey (Tanksuwan \& Mason, 2018), we investigate which dimensions have the strongest effect on BRMS user satisfaction.

The next section of the paper reviews related literature; this is followed by sections describing our research hypotheses, methodology, and findings respectively; and the final section offers our conclusions.

\section{Literature Review \& Theoretical Foundations}

Telecom operators face a dilemma; pricing strategies rooted in reduced minute rates and unlimited data caps doubtless attract new subscribers (and thus bolster market share) but can be counter-productive; more calls from more subscribers increase network infrastructure stress levels, leading to higher congestion rates, reduced quality of service and with it greater churn rates (Hassouna, Tarhini, Elyas, \& Saeed AbouTrab, 2015). Annual churn averages up to 67 percent in some countries, while the cost of acquiring new customers can be as much as 20 times higher than keeping them (Vafeiadis, 2015); so when they bale, companies lose not only future revenue, but also resources spent luring them in the first place (Hughes, 2007).

\footnotetext{
${ }^{1}$ In contrast, other system types, e.g., Enterprise Resource Planning may seem “optional extras” (especially) when resources are limited, even if they can yield efficiency benefits.
} 
Thus, business models are being reconfigured while product offerings grow ever more complex as operators vie to offer customers, the most attractive "service bundles". Ergo, IT agendas are in a constant flux to realize these services, both to entice new subscribers and to better manage and leverage those they already have (Niebuhr, Späne, Schröder, \& Gröne, 2010).

Moreover, today's network services greatly surpass basic voice and SMS, streaming, navigation and location sharing among others demand both extra bandwidth, and improved IT platforms in order to quickly develop, launch, and charge for new offerings, while keeping the "customer experience" positive. Retention surveys show that while price and product are important, subscribers mostly leave because of displeasure with their treatment (Hughes, 2007). Therefore, systems such as CRM and BRMS are critical to remaining competitive.

\section{Telecom Billing Systems Overview}

Integrated modular billing systems are now prevalent throughout the industry; a form of distributed enterprise application (He \& Da Xu, 2014) they support various business processes including collecting consumption data, credit control, calculating charges, producing customer bills, processing payments, and managing debt (Hunter \& Thiebaud, 2003). Nowadays, the generic term "billing system" is often refined thus Post-paid, Prepaid, and Convergent (Goldman, 2012). Post-paid billing supports subscribers using products and services on a monthly basis (Lin, Robert, Chiang, \& An Quek, 2016). Prepaid meanwhile describes a mechanism where customers pay in advance for services (Lin et al., 2016) and so do not receive an invoice but instead are charged in real-time. Finally, convergent billing refers to generating a unified view of all subscribed service charges (Mobile, Fixed, IP, etc.) within a single invoice (Ali \& Alhinai, 2015).

Billing system success, to the consumer, implies continued correctness! As such, the TM Forum (TMF), a global industry association that fosters collaboration to maximize success among telecoms providers, developed a framework and metrics by which companies can benchmark their existing operations. The framework proposes measurement of billing systems under three domains: revenue \& profit, customer experience, and operational efficiency (TM Forum, 2014)—similar in fact to constructs in the DeLone and McLean Model employed here. TMF also recommended tangible measurements under the four domains, such as average revenue per user, revenue unbilled, revenue overbilled, and churn rate. Another study into cloud-hosted billing systems (K. Park, Jaesun, Chung, \& K. H. Park, 2013) based success on such factors as integrity and non-repudiation capabilities, as well as non-obstructive and minimal computation costs. Further papers on BRMS success measures include Amdocs (2009) and Joshi et al. (2014).

\section{The Billing System Process}

The billing system process (or more precisely, group of processes) varies depending on providers' choice of system software and how, in turn, it interfaces with their network infrastructure. However, a simple process overview starts with activation of a new subscriber through an order management and fulfillment system which, in turn, interfaces with the billing system; the billing system itself then interfaces with a network inventory system that adds new phone numbers and IP addresses, etc. Hunter and Thiebaud (2003) outlined the stepwise billing system process flow as follows: Firstly, usage for customers activated on a network is passed to the billing system; next, usage data sent from several network elements are transformed into a common format. The rating engine then rates this data according to a pre-defined price. Following that, the calculation system collects all usage prices per customer and computes any applicable discounts or promotions applicable. A bill 
presentation module then creates the presentation format showing charges for that customer who receives their invoice in soft or hard copy. The process is completed by a function for managing accounts receivable payments. Thus, the system provides a module supporting payment and adjusts the balance accordingly. Where a payment is overdue, the system provides a function to handle outstanding balances, e.g., by blocking usage. BRMS can also support balance or usage adjustments in cases where the operator would like to compensate a customer for any reason.

\section{Billing System Software}

When choosing BRMS software, service providers can either purchase an off-the-shelf application tailored to their individual needs, or else developing a completely new system in house. Unsurprisingly, most companies opt for off-the-shelf solutions as they can deliver all necessary functionality (due to the modular architectures mentioned previously), combined with proven levels of dependability (Avienzis, Laprie, Randall, \& Landwehr, 2004).

Providers opting for in-house development face many challenges in terms of scalability, performance, and determining their future system road map. Since BRMS are non-volitional, they carry an enormous implementation risk (a point underscored by the collapse of Australian company OneTel as described in Avision and Wilson (2002). Poor quality systems can also negatively affect customer experiences, for example, through unexpected changes in products, bill shock, and disruptions to service (Friedrich, Péladeau, \& Muller 2015). In keeping with similar studies, Bloch, Blumberg, and Laartz (2012) showed that large software projects-including BRMS—-finish up challenged or failed (based on schedule, cost, and scope), running as much as 66 percent over budget and 33 percent behind schedule.

Regardless of whether built in house, bespoke, or off-the-shelf/vendor adapted, billing systems represent a major investment. Typically, they have a lifespan of around 10 years (minimum) from deployment to decommissioning during which they are integral to strategic positioning of any telecoms service provider (Tam \& Tomala, 2001). The interesting point here is that unlike many other types of system, relatively few new BRMS are deployed each year (Katz, 2008) thereby limiting opportunities to learn from past mistakes.

\section{Theoretical Foundation: DeLone \& McLean Model of Information Systems Success}

Our theoretical foundation here is a conceptual model by DeLone and McLean (1992). That particular model is built on an existing taxonomy by Mason (1978), itself a modification of Shannon and Weaver's Information Theory (1949). Working from Mason's taxonomy, DeLone and McLean proposed six IS success dimensions: system quality, information quality, use, user satisfaction, individual impact, and organizational impact. For each dimension, the authors identify, categorize, and analyze appropriate success measures.

DeLone and McLean's model was subsequently evaluated in several domains to validate and contribute to its refinement, with nearly 300 peer-reviewed articles reporting on their findings. However, many such works only represent partial evaluations, using cherry-picked subsets of relationships between the IS success dimensions (often leading to corollary misconceptions that subsequent works propagated). In fact, only a brace of publications (Seddon, Kiew, \& Patry, 1994; Rai et al., 2002) actually sought to validate the entire model, both conducted at individual level.

Despite these caveats and some criticism (Seddon, 1997; Pitt, Watson, \& Kavan, 1995), the overwhelming weight of literature backed the DeLone \& McLean Model. That said, Myers, Kappelman, and Prybutok (1997) 
and Peter, Sandy, Ravi, and Matthew (1999) observed how while individual and organizational benefits feature in the model, wider benefits, for example, to industry or society at large, do not. Consider how dynamic pricing engines are profiting the airline industry by enhancing revenue generating capabilities (Wittman \& Belobaba, 2016). Or the benefits of technology have brought to mankind, e.g., in health care, education, and communication, while revolutionizing productivity, entertainment, and avenues for political engagement (Turkle, 2017).

Following 10 years validation, DeLone and McLean (2003) published an updated model incorporating feedback received. The revised model again defines six dimensions: system quality, information quality, service quality, use, user satisfaction, and perceived net benefits. While very similar, the revised model featured two significant changes. The first revision, acknowledging Pitt et al. (1995), saw inclusion of a "service quality" dimension. Secondly, incorporating Seddon's (1997) suggestion, DeLone and McLean (2003) generalized the individual and organizational impact measures into a single dimension termed "net benefits", thereby enabling benefits to be considered at individual, organizational, industry, and societal levels.

A meta-analysis by Petter, DeLone, and McLean (2008) later evaluated the state of DeLone and Mclean's model including the strength of relationships between dimensions. The authors proposed 14 hypotheses covering empirical research published between 1992 and 2007. Results show support for the majority of hypotheses implied at the individual level of analysis for net benefits, but only one relationship at the organizational level (which are markedly different in comparison). In addition, few studies were found to measure and account for multiple dimensions of success (and interrelationships among them); hence our motivation in this paper where we empirically test for net benefits at organization level.

Several studies specifically consider levels of effect between user satisfaction and system, service, and information quality. Among them, a study on e-government systems by Wang and Laiu (2008) found that information quality has the strongest effect on user satisfaction followed by service quality. A further review of knowledge management systems (Wang \& Yang, 2016) identified service quality as impacting strongest on user satisfaction, with system quality having least impact. Montesdioca and Maçada (2015) meanwhile showed that only information quality is positively associated with user satisfaction in an information security context. In a study of e-learning systems in Pakistan, Kanwal and Rehman (2016) demonstrated that system quality contributes most to user satisfaction followed closely by information quality. Finally, the findings of a study by Alshibly (2014) evaluating e-HRM systems showed that information quality and system quality respectively have the highest effect on user satisfaction. When viewed collectively, it is evident that information quality is frequently either the most significant or subsequent influencer of user satisfaction.

As previously indicated, this paper assesses BRMS success using the 2003 manifestation of DeLone and McLean's model. However, while further validation may seem unnecessary, our belief is that there are areas still to be explored. We touched on certain aspects of this during the introduction. Certainly to date and to the best of our knowledge, no application considered in the literature qualifies as business critical, at least not enough to trigger the demise of an entire company (cf. OneTel). Moreover, only one study (Iivari, 2005) has previously investigated NVS, which in contrast to this paper, reported on a study of one mandatory system (Accounting \& Finance), in one specific organizational context (Oulu Council municipality, Finland) thereby raising questions of whether the findings were particular to that system and context. 


\section{Research Hypotheses}

Figure 1 illustrates the research model developed for this study to measure and explain BRMS success by user satisfaction. It defines success in terms of four dimensions-information quality, system quality, service quality, and user satisfaction — each having multiple success indicators.

\section{Hypothesis 1}

H1: Information quality focuses on quality of output generated by BRMS. Examples include amount charged in a bill, billing reports, and other financial information. Inputs meanwhile feature a mechanism to verify call detail records before allowing data into the system. A previous study showed solid support for the association between information quality and user satisfaction (R. Schppers, H. Schppers, \& Ngwenyama, 2006). We therefore proposed that this study also tests whether the same is true for BRMS.

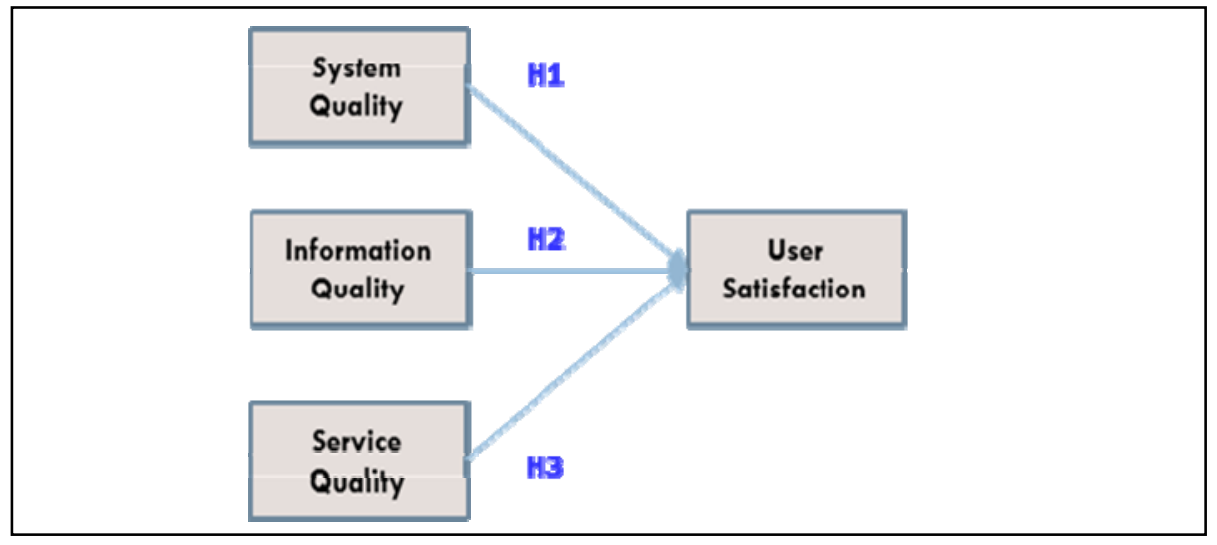

Figure 1. Proposed model for evaluating user satisfaction of BRMS.

\section{Hypothesis 2}

Service quality considers overall system support provided by an organization's IT department and the BRMS product owner, as well as items facilitating ease of use including such aspects as responsiveness of product owner, reliability of billing vendor service, and empathy and competence of IT staff. An earlier study indicated that service expectancy has a positive influence on user satisfaction (Thong, Yap, \& Raman, 1996). Again, therefore this study also tests whether the same is true for BRMS.

\section{Hypothesis 3}

Finally, system quality alludes to desired characteristics of BRMS including performance and functionality geared towards saving user effort. Quality embodies aspects, such as system turnaround time and system features, including, real-time rating and accuracy. An earlier study investigating information systems success demonstrated a positive impact of system quality on user satisfaction (Schppers et al., 2006). So once again, this study also tests whether the same is true for BRMS.

\section{Research Methodology}

This section describes the construct measurement, sampling, data collection, and data analysis methods applied in our work. Construct measurement seeks to identify appropriate measures for each model construct. Once identified, they were used to develop a questionnaire in order to form data from various BRMS stakeholders. Next, structural equation modeling (SEM) was used to test the data we obtained. 
Previously, validated indicators from existing literature were employed as means of developing measurement indicators for each dimension in our proposed model. These indicators are summarized in Table 1 and were subsequently used to develop a questionnaire using a five-point Likert scale, ranging from $1=$ "Strongly disagree" to 5 = "Strongly agree".

In a primer on the topic, Hair, Hult, Sarstedt, and Ringle (2013) advocated use of component-based Structured Equation Modeling (SEM) or Partial Least Squares (PLS) modeling for exploratory research where the objectives include estimating complex cause-effect relationship among latent variables; this aligns with the objectives of this paper making it an obvious choice. PLS-SEM is a structured equation modeling technique capable of analyzing models involving multiple-item dimensions, with direct and indirect paths. It can simultaneously evaluate both the measurement model and the structural model with the aim to minimize error variance (Hair et al., 2013).

A PLS-SEM consists of two elements: Firstly, the structural model represents the constructs and relationships or paths between these constructs; secondly, the measurement models of the constructs display the relationships between constructs or dimensions and indicator variables. In this study, there are four measurement models and one structural model linking our four dimensions. For the purpose of our investigation, SmartPLS professional software was used to analyze and estimate the parameters in the measurement models and structural model.

Westland (2010) recommended as the minimum sample size, using 10 times the largest number of formative indicators to measure a single dimension; in this case, 40 was the target minimum sample size. Participants in our survey comprised IT workers, marketing personnel, and business users from seven telecom operators in Thailand whose market share collectively exceeds $98 \%$ of all subscribers throughout the country.

We validated our questionnaire by using the index of Item-Objective Congruence (IOC) developed by Rovinelli and Hambleton (1977), a procedure used in test development for evaluating content validity at the item development stage. This measure is limited to assessment of one-dimensional items or items that measure specified composites of skills. After validation, the questionnaire was launched as an online survey to target participants. BRMS experts and representatives from the telecom operators joined the IOC test in order to ensure clarity of the questions and hence overall quality of the questionnaire. Rovinelli and Hambleton (1977) advised an IOC score greater than or equal to 0.5 is appropriate.

Table 1

Indicators for Each Dimension

\begin{tabular}{lll}
\hline Dimensions & Measures & References \\
\hline & Correct Output from System (IQ1) & Iivari (2005); Bailey \& Pearson (1983) \\
& Sufficient Data (IQ2) & McKinney, Kanghyun, \& Zahedi (2002) \\
Information Quality & Timeliness of Data (IQ3) & Iivari (2005); Bailey \& Pearson (1983); Gable, \\
& Consistency Data Output (IQ4) & Sedera, \& Chan (2008) \\
& Correct Input to System (IQ5) & Iivari (2005) \\
& System Accuracy (SY2) & Iivari (2005); Bailey \& Pearson (1983) \\
\multirow{2}{*}{ System Quality (SY) } & System Performance (SY5) & Gable et al. (2008); Sedera \& Gable (2004) \\
& Sufficient Features to Replace Existing System (SY6) & Gable et al. (2008) \\
& Customization Capability (SY7) & Gable et al. (2008); Sedera \& Gable (2004) \\
& &
\end{tabular}


(Table 1 to be continued)

\begin{tabular}{lll}
\hline & Accountability (SV1) & Chang \& King (2005) \\
& Knowledge Capability (SV2) & Pitt et al. (1995) \\
Service Quality (SV) & Assurance to Support (SV3) & Pitt et al. (1995) \\
& Assurance to Fix Issue (SV4) & Pitt et al. (1995) \\
& Meet the Standard Policy Defined by the Operator (SV5) & Chang \& King (2005) \\
& Training Users to be Ready (SV6) & Norris (1998) \\
& Fast response time (US1) & Almutairi \& Subramanian (2005) \\
& Bill Shock or Incorrect Bill (US2) & Joshi (2014) \\
User Satisfaction (US) & Gable et al. (2008) \\
& Function Correctly as Requirements (US4) & Gable et al. (2008) \\
\hline
\end{tabular}

Next, we sought permission to contact their staff from directors of the service providers involved conducting the survey. Results were assessed for both the measurement models and structural model. Following Hair et al. (2013), the statistical values from the analysis were then compared with the recommended values as shown in Table 2 in order to conclude the validity of measures and model.

Table 2

Criteria of Statistical Model Assessment

\begin{tabular}{llll}
\hline Assessment & \multicolumn{1}{c}{ Criterion } & Value & References \\
\hline Indicator reliability & Outer loading & $>0.708$ & (Hair et al, 2013) \\
Internal consistency reliability & Composite reliability & $>0.7$ & (Hair et al, 2013) \\
Convergence validity & Average variance extracted & $>0.5$ & (Hair et al, 2013) \\
& & & Larcker, 1981) \\
Discriminant validity & Square root of AVE & $>$ correlations of latent & (Fornell and \\
& & $>1.96$ (0.05 level with & (Hair et al, 2013) \\
$\begin{array}{l}\text { Significance and relevance of } \\
\text { model relationship }\end{array}$ & $\begin{array}{l}\text { Significant of path } \\
\text { coefficients }\end{array}$ & two-tailed test) & (Chin, 1998) \\
$\begin{array}{l}\text { Level of coefficient of } \\
\text { determination }\end{array}$ & Level of $\mathrm{R}^{2}$ value & $>.67$ substantial, & $>.33$ average, \\
\end{tabular}

\section{Research Findings}

This subsection presents the findings from our research, including IOC questionnaire testing, results of data collection, and assessment of the measurement models, structural model proposition testing, and overall effect of the three quality dimensions on user satisfaction.

\section{Questionnaire Validation}

Five experts in the area of BRMS were used in conducting our Item-Objective Congruence questionnaire validation, with seven users involved in our pilot survey test. The experts performed IOC testing to affirm clarity of questions featured in the questionnaire. Results clearly showed that all IOC test scores for all questions were above 0.5 . Thus, those questions were deemed suitable to use for the survey. After completing 
the IOC test, a pilot survey was conducted involving seven selected users. Feedback from the pilot revealed a need to remove ambiguities from three questions. After modifying those questions, the results of our questionnaire validation, including IOC and pilot survey test, proved the questionnaire was now of sufficiently good quality to perform a detailed survey.

\section{Data Collection Results}

The questionnaire was sent to 120 BRMS stakeholders in order to ascertain views on BRMS success inside their respective organizations. For each question, participants were asked to select the response which best described their level of agreement. All participants partook on an entirely voluntarily basis. Ninety-two samples were returned with an effective ratio of $72 \%$. Results showed that $30 \%$ of respondents had seven years or more experience, $49 \%$ between three and seven years, with just $21 \%$ having less than three years. In addition, they were working for three distinct types of telecom operator: mobile service only, fixed line \& broadband services, or fixed line, broadband, and mobile services. This covers all categories of telecom operator in Thailand.

\section{Assessment of Measurement Models}

The measurement model consisted of the constructs, indicators, and relationships between indicators and constructs. As stated previously, in this study, there were four measurement models. Firstly, we tested the reliability of all indicators in each dimension by using outer loading. The indicator's outer loadings should be higher than 0.5 (Hair et al., 2013). Results were higher than its highest correlation with any other models. Thus, there is discriminant validity between all the measurement models. In conclusion, therefore, it can be said all four measurement models were acceptable given the assessment criteria were met

\section{Structural Model Proposition Testing}

We then evaluated the structural model to test our hypotheses. Two measures were used: statistical significance ( $t$-tests) of the estimated path coefficients and the ability of the model to explain variance in the dependent variables $R$ squared $\left(R^{2}\right)$. To test the significance of our hypotheses, the rule proposed by Hair et al. (2013) was followed; namely that a $t$-value $>1.96$ is significant at the $95 \%$ confidence level. The results showed that information quality had a $t$-value of 5.616, system quality a $t$-value of 3.456 , and service quality a $t$-value of 5.734. Therefore, all quality dimensions were found to have a significant impact on user satisfaction. $R^{2}$ attempts to measure the explained variance of the dependent variable relative to its total variance. Chin (1998) contended that an $R^{2}$ value $>0.67$ implies substantial, $0.67>R^{2}$ value $>0.33$ implies average, and $0.33>R^{2}$ value $>0.19$ implies weak. The coefficient of determination values for user satisfaction was 0.791 .

\section{Effect Between the Three Quality Dimensions and User Satisfaction}

After examining the significance of the relationships, it was important to assess the relevance of those relationships. Structural model path coefficients can be interpreted relative to one another. If one path coefficient is larger than another path, its effect on the endogenous latent variable is greater; this is known as the "total effect".

The results shown in Table 3 revealed that total effect of service quality on user satisfaction was 0.405 which was the highest number compared to the other constructs. Thus, service quality exhibited a stronger effect on user satisfaction than both information quality and system quality. 
Table 3

Total Effect Between Constructs

\begin{tabular}{ll}
\hline Quality dimensions & User satisfaction \\
\hline Information Quality & 0.357 \\
Service Quality & 0.405 \\
System Quality & 0.251 \\
\hline
\end{tabular}

\section{Conclusions \& Future Work}

The results indicate that information quality, system quality, service quality, and user satisfaction are all valid measures of BRMS success. Hypothesized relationships between the four success dimensions were significantly substantiated. This corresponds with results of other studies (DeLone \& McLean, 2003; Urbach \& Müller, 2011). The study also identified five measures of information quality, four measures of system quality, four measures of service quality, and four measures of user satisfaction. The measures for information quality were correct output, sufficient data, timeliness of data, consistency of output, and correct input to (the) system. The four measures of system quality were system accuracy, system performance, sufficient features to replace (an) existing system, and customization capability. Measures of service quality were accountability, knowledge capability, assurance to support, assurance to fix issue, meet standard policy, and training of users. And finally, the four measures of user satisfaction were fast response time, (extent of) bill shock, defects, and (system) functioning correctly.

Once the proposed model had been successfully validated, we tested the level of significance among user satisfaction and the three quality dimensions. Results showed that service quality had the strongest influence on user satisfaction, with information quality second. This finding is quite different from other applications found in our literature review which mostly have information quality as having the strongest impact (knowledge management systems apart). It means that level of effect between user satisfaction and the three dimensions depends on type of application. One expects that complex system, like BRMS requires better service quality than other, easier to use application.

Our main research contribution in this paper is further empirical testing of the DeLone and McLean's IS success model in respect of user satisfaction for BRMS. This study is also, to the best of our knowledge, the first to empirically validate a comprehensive success model for BRMS as well as contributing fresh knowledge relating to success measurement for enterprise systems in the Telecoms sector generally. Thus, our study advances theoretical development of such systems (thereby yielding more effective use of time and other resources), also serving as a basis for future research in this field.

From a practical point of view, our findings highlight a need for organizations to focus on the service aspect of BRMS towards enhancing user satisfaction. The study may be extended to cover a complete D \& M Model evaluation covering areas, such as intention to use and net benefits to an organization in order to understand which factor(s) have the strongest effect on the success of telecom service providers. Further and perhaps more significantly, the experiments could be extended to other countries, with results compared to those for Thailand, while the impact on the telecoms industry as a global entity and also impact on society at large could also be explored.

\section{References}

Ali, M., \& Alhinai, Y. (2015). Exploring mobile commerce adoption maturity: An empirical investigation. Americas Conference on Information Systems, 13-15 August, Fajardo, Puerto Rico. 
Almutairi, H., \& Subramanian, G. (2005). An empirical application of the DeLone \& McLean Model in the Kuwaiti Private Sector. Journal of Computer Information Systems, 13, 318-340.

Alshibly, H. (2014). Evaluating E-HRM success: A validation of the information systems success model. International Journal of Human Resource Studies, 4(3), 107-124.

Amdocs. (2009). The value of billing transformation in an economic downturn. Retrieved from https://web2.amdocs.com/Whitepapers/General/

Avienzis, A., Laprie, J. C., Randall, B., \& Landwehr, C. (2004). Basic concepts \& taxonomy of dependable \& secure computing. IEEE Transactions on Dependable \& Secure Computing, 1(1), 11-33.

Avison, D., \& Wilson, D. (2002). IT failure and the collapse of OneTel. In R. Traunmuller (Ed.), Information systems: The e-business challenge (pp. 31-46). Dordrecht, The Netherlands: Kluwer Academic Publishers.

Bailey, J., \& Pearson, S. (1983). Development of a tool for measuring \& analyzing computer user satisfaction. Management Science, 29(5), 530-545.

Bloch, M., Blumberg, S., \& Laartz, J. (2012). Delivering large-scale IT projects on time, on budget \& on value. Retrieved from https://www.mckinsey.com/business-functions/digital-mckinsey/our-insights/delivering-large-scale-it-projects-on-time-on-bu dget-and-on-value

Chang, J., \& King, W. (2005). Measuring the performance of information systems: A functional scorecard. Journal of Management Information Systems, 22(1), 85-115.

Chin, W. (1998). The partial least squares approach to structural equation modeling. In G. Marcoulides (Ed.), Methodology for business \& management, modern methods for business research (pp. 295-336). Mahwah, NJ: Lawrence Erlbaum Associates.

DeLone, W., \& McLean, E. (1992). Information systems success: The quest for the dependent variable. Information Systems Research, 3(1), 60-95.

DeLone, W., \& McLean, E. (2003). The DeLone \& McLean Model of information systems success: Ten-year update. Journal of Management Information Systems, 19(4), 9-30.

Friedrich, R., Péladeau, P., \& Muller, K. (2015). Chief digital officers in the telecom industry. Retrieved from https://www.strategyand.pwc.com/media/file/Chief-digital-officers-in-the-telecom-industry.pdf

Gable, G., Sedera, D., \& Chan, T. (2008). Re-conceptualizing information system success: The IS-impact measurement model. Journal of the Association for Information Systems, 9, 377-408.

Goldman, L. (2012). Telecoms software: Software strategies that impact operator business results. Retrieved from http://www.analysysmason.com/PageFiles/35474/

Hair, J., Hult, G., Sarstedt, M., \& Ringle, C. (2013). A primer on partial least squares structural equation modelling (PLS-SEM). Thousand Oaks, CA: Sage Publication.

Hassouna, M., Tarhini, A., Elyas, T., \& Saeed AbouTrab, M. (2015). Customer churn in mobile markets: A comparison of techniques. International Business Research, 8(6), 224-237.

He, W., \& Da Xu, L. (2014). Integration of distributed enterprise applications: A survey. IEEE Transactions on Industrial Informatics, 10(1), 35-42.

Hughes, A. (2007). Customers churn customer retention for telecoms. Förlag: Racom Communications.

Hunter, J., \& Thiebaud, M. (2003). Telecommunications billing systems: Implementing and upgrading for profitability, professional telecommunications. New York: McGraw-Hill.

Iivari, J. (2005). An empirical test of the DeLone-McLean Model of information system success. Advances in Information Systems, $36,8-27$.

Jin, J., Gubbi, J., Marusic, S., \& Palaniswami, M. (2014). An information framework for creating a smart city through Internet of Things. IEEE Internet of Things Journal, 1(2), 112-121.

Joshi, S., Sohag, S., Sarkar, D., Dewan, T., Chintan, D. Shubham, P., \& Sumit, G. (2014). Impact of over the top (OTT) services on telecom service providers. Indian Journal of Science and Technology, 8(S4), 145-160.

Kanwal, F., \& Rehman, M. (2016). Measuring information, system \& service qualities for the evaluation of e-learning systems in Pakistan. Pakistan Journal of Science, 68(3), 302-307.

Katz, R. L. (2008). Why are CRM and billing systems implementation projects in the telecommunications industry so prone to failure? Retrieved from http://www.teleadvs.com/wp-content/uploads/articles/new_paper.pdf

Lang, R., \& Welker, R. (2002). Assessing the validity of IS success models: An empirical test and theoretical analysis. Information Systems Research, 13(1), 50. 
Lin, T., Robert, J., Chiang, H., \& An Quek, R. (2016). Examining perceived value of location-based mobile advertising applications among Taiwanese smartphone users. The 66th International Communication Association Annual Conference, 9-13 June 2016, Fukuoka, Japan.

Mason, R. (1978). Measuring information output: A communication systems approach. Information \& Management, 1(4), $219-234$.

McKinney, V., Kanghyun Y., \& Zahedi, F. (2002). Measurement of web-customer satisfaction: An expectation \& disconfirmation approach. Information Systems Research, 13(2), 296-315.

Montesdioca, G., \& Maçada, A. (2015). Quality dimensions of the DeLone-Mclean Model to measure user satisfaction: An empirical test on the information security context. The 48th Hawaii International Conference on System Sciences, 5-8 January, Hawaii, USA.

Myers, B., Kappelman L., \& Prybutok, V. (1997). Comprehensive model for assessing the quality and productivity of the information system function: Toward a contingency theory for information systems assessment. Information Resources Management Journal, 10(1), 6-25.

Niebuhr, J., Späne, A., Schröder, G., \& Gröne, F. (2010). Evolution or revolution? Strategies for telecom billing transformation. Retrieved from http://www.strategyand.pwc.com/reports/

Norris, R. (1998). Managing the transition period from old to new billing systems. Retrieved from http://www.billingworld.com/articles/1998/02/

Park, K., Jaesun, H., Chung, W., \& Park, K. H. (2013). A mutually verifiable billing system for the cloud computing environment. IEEE Transactions on Services Computing, 6(3), 300-313.

Pati, R., Dadhich, L., Basile, V., \& Schreiber, B. (2017). Reimagining Telco operations in a hyper-digital world. Retrieved from http://www.adlittle.de/en/FutureofTelcoOps

Peter, B. S., Sandy, P., Ravi, S., \& Matthew, B. (1999). Dimensions of information systems success. Comm. AIS, 2(3).

Petter, S., DeLone, W., \& McLean, E. (2008). Measuring information systems success: Models, dimensions, measures, and interrelationships. European Journal of Information Systems, 17(3), 236-263.

Pitt, L., Watson, R., \& Kavan, C. (1995). Service quality: A measure of information systems effectiveness. MIS Quarterly, 19(2), 173-187.

Rai, A., Lang, S. S., \& Welker, R. B. (2002). Assessing the validity of is success models: An empirical test and theoretical analysis. Information Systems Research, 13(1), 50-69.

Rovinelli, R., \& Hambleton, R. (1977). On the use of content specialists in the assessment of criterion-referenced test item validity. Dutch Journal of Education Research, 2, 49-60.

Schppers, R., Schppers H., \& Ngwenyama, O. (2006). Contextual influences on user satisfaction with mobile computing: Findings from two healthcare organizations. European Journal of Information Systems, 15, 261-268.

Seddon, P., Kiew, M., \& Patry, M. (1994). A partial test and development of the DeLone and Mclean Model of IS success. Retrieved from https://pdfs.semanticscholar.org/db81/d80988eb845bf5c874927013e86ab59fea6b.pdf

Seddon, P. (1997). A re-specification and extension of the DeLone and Mclean Model of IS success. Information Systems Research, 8(3), 240-253.

Sedera, D., \& Gable, G. (2004). A factor \& structural equation analysis of the enterprise systems success measurement model. The International Conference on Information Systems, 12-15 December, Washington D.C., USA.

Shannon, C., \& Weaver, W. (1949). The mathematical theory of communication. Urbana, IL: University of Illinois Press.

Tam, M. C. Y., \& Tummala V. M. R. (2001). An application of the AHP in vendor selection of a telecommunications systems. Omega International Journal of Management Science, 29(2), 171-182.

Tangsuwan, A., \& Mason, P. (2018). Improving user satisfaction of future telecom billing \& revenue management systems. The 7th International Conference on Business, Economics \& Communication, 29-30 November, Phitsanulok, Thailand.

Thong, Y., Yap, C., \& Raman, K. (1996). Top management support, external expertise \& information systems implementation in small businesses. Information Systems Research, 7(2), 248-267.

TM Forum. (2014). Frameworx best practice: Business Metrics Scorecard (BMS): Business Metrics Solution Suite 2.1. Princeton, NJ: TM Forum Office.

Turkle, S. (2017). Reclaiming conversation: The power of talk in a digital age. New York, NY: Penguin Press.

Urbach, N., \& Müller, B. (2011). The updated DeLone and McLean Model of information systems success. Information System Theory, 28, 1-18.

Vafeiadis, T., Diamantaras, K. I., Sarigiannidis, G., \& Chatzisavvas, K. C. (2015). A comparison of machine learning techniques for customer churn prediction. Simulation Modelling Practice and Theory, 55, 1-9. 
Wang, M., \& Yang, T. (2016). Investigating the success of knowledge management: An empirical study of small and medium-sized enterprises. Asia Pacific Management Review, 21, 79-91.

Wang, Y., \& Liao, Y. (2008). Assessing e-government systems success: A validation of the DeLone and McLean Model of information systems success. Government Information Quarterly, 25, 717-733.

Westland, J. (2010). Lower bounds on sample in structural equation modeling. Electronic Commerce Research and Applications, 9(6), 476-487.

Wittman, M., \& Belobaba, P. (2016). Dynamic availability of fare products with knowledge of customer characteristics. Journal of Revenue and Pricing Management, 16(10). 